\title{
Cellular damage and apoptosis along with changes in NF-kappa B expression were induced with contrast agent enhanced ultrasound in gastric cancer cells and hepatoma cells
}

Zao Jiang ${ }^{1,4}$, Wei $W^{2,4^{*}}$ and Meng-lu Qian ${ }^{3}$

\begin{abstract}
Background: The effect of cell injury and apoptosis induced by ultrasound with contrast agent has been verified. Contrast agent enhanced apoptosis and expression of genes that related to apoptosis and are responsive to ultrasound. This effect was associated with reactive oxygen species (ROS) production induced by the sonochemical reaction, as reported in previous studies. NF-kappa B may be one of the factors involved in oxidizing reactions or modulation during the process of ultrasound inducing apoptosis.
\end{abstract}

Results: Ultrasound irradiated gastric cancer cells (SGC7901 cell line) and hepatocellular carcinoma cells (SMMC-771 cell line) cultured in medium containing contrast agent. Significant cellular damage and apoptosis were observed in the bath cells incubated for 24 hours following 120 seconds ultrasonic irradiation. I kappa B alfa expression synchronously increased in the treatment groups of both the cell lines, and the down-regulated expression of NFkappa B influenced its-regulated expression of genes that related to apoptosis. Production of intracellular ROS and elevation of NF-kappa B level occurred after incubation of the cells for 1 hour following ultrasonic treatment.

Conclusions: Our result suggested that contrast agent enhanced the biological effect of ultrasound. Their reaction might stimulate the transitory expression of NF-kappaB, and subsequent elevation in $\mid \kappa B$ Balfa expression could lead to the apoptosis of SGC7901 cells and SMMC-771 cells.

Keywords: Ultrasound, Contrast agent, Apoptosis, NF-kappa B, Cancer cell

\section{Background}

Studies regarding the ultrasonic effects on the proliferation of cells have gradually led to the development of a new field of ultrasonic biological research and promoted the emergence of a new direction for ultrasonic medical therapy [1]. Furthermore, low-frequency ultrasonic (20 khz-2 Mhz) irradiation has the ability to directly kill tumor cells including inhibiting tumor cell proliferation and inducing apoptosis $[2,3]$. The mechanism of inhibition of tumor cell growth may be related to the cavitation effect of lowfrequency ultrasound, because free radicals, produced via the cavitation effect, interrupt the replication of normal

\footnotetext{
* Correspondence: 101005800@seu.edu.cn

${ }^{2}$ Key Laboratory of Environmental Medicine and Engineering, Minister of Education, Public health college, Southeast University, Nanjing, China Full list of author information is available at the end of the article
}

double-stranded deoxyribonucleic acid (DNA) by promoting the polymerization of DNA strand and restrain cell growth [4]. The biomechanics study regarding the dynamic characteristics of an ultrasound contrast agent suggested that ultrasound irradiation with a microbubble contrast agent may cause cellular injury[5]. In combination with a microbubble contrast agent, ultrasound might promote cellular injury, including the initiation of apoptosis and cell injuries through ultrasonic cavitation effects or via other approaches [6-8].

In previous studies, free radicals were considered to be the main products of ultrasonic irradiation with microbubble agent and as an important factor responsible for cellular injury caused by ultrasound treatment $[9,10]$. Free radicals, including reactive oxygen species (ROS), can also activate some cellular factors such as nuclear factor kappa
C Biomed Central

(c) 2012 Jiang et al; licensee BioMed Central Ltd. This is an Open Access article distributed under the terms of the Creative Commons Attribution License (http://creativecommons.org/licenses/by/2.0), which permits unrestricted use, distribution, and reproduction in any medium, provided the original work is properly cited. 
B (NF-kappa B); NF-kappa B is one of the cellular factors primarily involved in oxidizing reactions or in inducing "oxidative stress"[11,12]. Although NF-kappa B is known to modulate the signaling pathways responsible for cellular proliferation and degeneration, its activity is regulated by the binding of a cytoplasmic inhibitor protein, I kappa B [13-15]. However, such alterations in the levels of these factors have been not reported when cells are subjected to ultrasound irradiation with contrast agent.

In order to determine the biological effects and changes in the levels of relevant cellular factors and to elucidate the possible mechanism underlying the effects of low-frequency ultrasound combined with microbubble agents, we used a contrast agent Levovist to determine the changes in the expressions of NF-kappa B and I kappa B in cultured gastric cancer cells and hepatocellular carcinoma cells subjected to low-frequency ultrasound irradiation.

\section{Results}

\section{Test of inhibiting cells proliferation}

The cells were incubated for 24 hours after ultrasonic irradiation for 60, 90, 120 and 150 seconds, the lowest cell survival rates were observed in the cells irradiated for 120 seconds compared with those of the control group. The survival rate of the SMMC-7721 cells was $51.52 \pm 3.51 \%$ and that of the SGC-7901 cells was 49.63 $\pm 4.21 \%$. Similar results were obtained when the cells were irradiated for 120 seconds with ultrasound and contrast agent after incubation for 1, 24 and 48 hours.

\section{Ultrasound-induced changes in the intracellular levels of reactive oxygen species (ROS) and superoxide dismutase (SOD) in the medium containing the contrast agent}

Ultrasound irradiation of the cells cultured in the medium containing contrast agent led to the production of ROS and abatement of SOD activity. Significant effects were observed at 1 hour incubation after 120 seconds of ultrasonic exposure. In SGC7901 cells, Changes in the intracellular levels of ROS were significantly (81.40 \pm 1.31 for group D vs. $23.20 \pm 1.22$ for group A after incubation for $60 \mathrm{~min}, p<0.05)$ and $\operatorname{SOD}(69.52 \pm 2.81 \mathrm{U} / \mathrm{ml}$ for group D vs. $165.06 \pm 1.14 \mathrm{U} / \mathrm{ml}$ for group A after incubation for $60 \mathrm{~min}, p<0.05)$. Similar changes occurred in SMMC-7721 cells after incubation for 1 hour. The intracellular level of ROS was increased $(77.40 \pm 1.1$ for group D vs. $23.20 \pm 1.2$ for group A, $p$ $<0.05)$, and the level of SOD was decreased (58.87 \pm 1.91 for group D vs. $149.15 \pm 5.72 \mathrm{U} / \mathrm{mL}$ for group $\mathrm{A}, p$ $<0.05$.).

Morphological changes of cellular damage and apoptosis Both SGC7901 and SMMC-7721 cells showed different kinds of changes in cellular morphology after treatment with ultrasound combined with microbubble agent. The main morphological changes observed in the cells were as follows: mitochondria swelling or vacuolation with disappearance of mitochondria cristae, cytoplasmic rarefaction, formation of vacuoles of various sizes, reduced electron density matrix, and dilation of endoplasmic reticulum. Apoptosis was also observed in some cells showing characteristic apoptotic features of cell shrinkage and cytoplasmic condensation, blistering of cytoplasm, formation of apoptotic bodies, nuclear condensation, and assembly of nuclear chromatin toward the inner surface forming clumps or crescentshaped bolus. As demonstrated, treatment by ultrasound with contrast agent induced typical apoptotic morphological changes, including orange cell shrinkage with condensation and fragmentation of nuclei (Figure 1).

\section{Flow cytometry-based confirmation of apoptosis in cells} after treatment with both ultrasound and contrast agent The apoptosis rates in the SMMC-7721 cells treated with ultrasound and microbubble agent were significantly higher $(27.31 \pm 4.14)$ than those in group A (1.69 $\pm 0.27, P<0.05)$, group B $(2.51 \pm 0.32$,), and group $C$ $(15.24 \pm 2.16)$. Similar results were observed in the SGC7901 cells. The apoptotic rates in SGC7901 cells in group D $(21.15 \pm 4$. 68) were significantly lesser than those in group A $(1.15 \pm 0.37 P<0.05)$, group B $(2.39 \pm$ 0.65 ,), and group $C(11.7 \pm 2.68)$ (Figure 1$)$.

\section{Western blot analysis showed the transient expression of NF-kappa B in the cells treated with ultrasound and contrast agent}

Similar results were obtained in both SMMC-7721cells and SGC7901 cells. NF-kappa B expression levels in both cells were remarkably higher than that of control group when the cells were incubated for 1 hour after 120 seconds treatment with ultrasound and contrast agent. At the same time, I kappa B-alfa expressed indistinctly. However, enhanced expression of I kappa B-alfa was observed when the cells were incubated for 24 hours after the treatment. Meanwhile decreased expressions of NF-kappa B and bcl-2 were observed respectively in the both cell lines, and reciprocal expression of bax also emerged in those cells (Figure 2).

\section{Discussion}

Ultrasonic microbubble contrast agent might produce biological effects on cells, because such agents are able to induce cellular and cell membrane injuries $[1,6]$. ROS induced by ultrasound irradiation are thought be responsible for the biological effects of ultrasound irradiation [16,17]. Ultrasonic microbubble contrast agents have the ability to produce oxyradicals, which has been confirmed by spin resonancespectroscopy [18]. These 


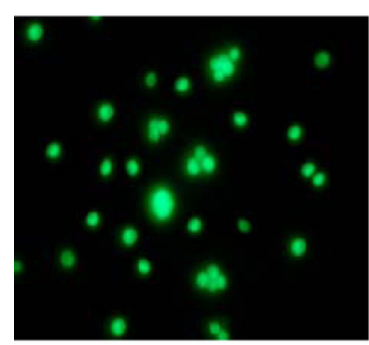

a-1

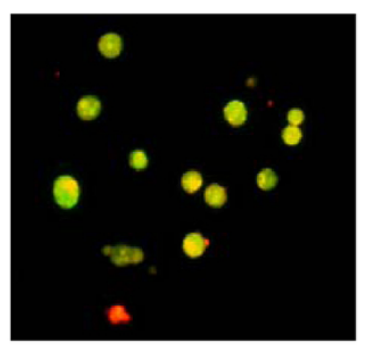

a-2

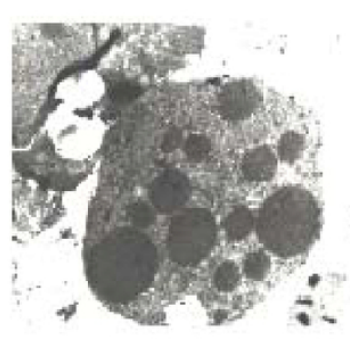

a-3

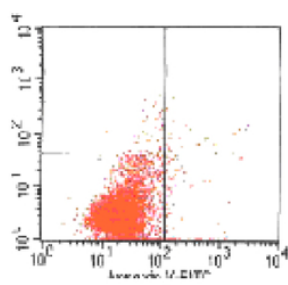

A

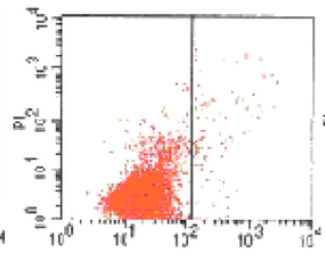

B

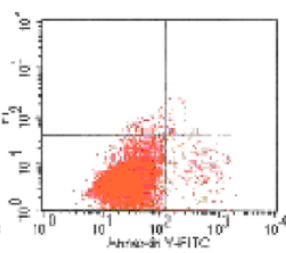

C

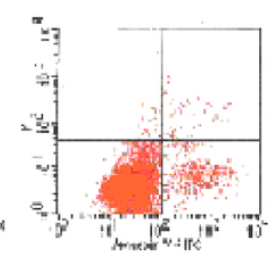

D

a-4

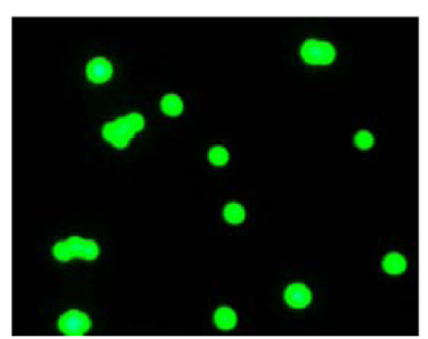

b-1

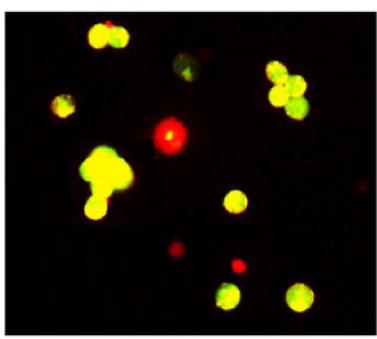

b-2

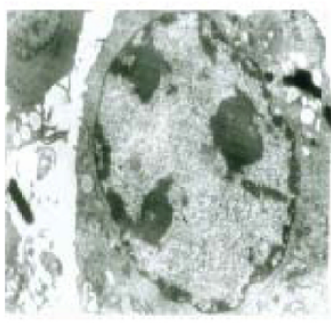

b-3

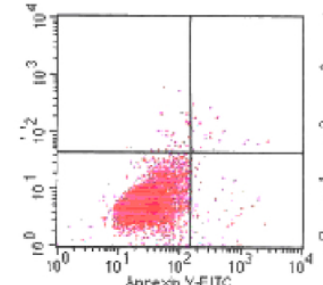

A

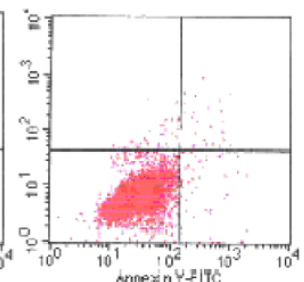

B

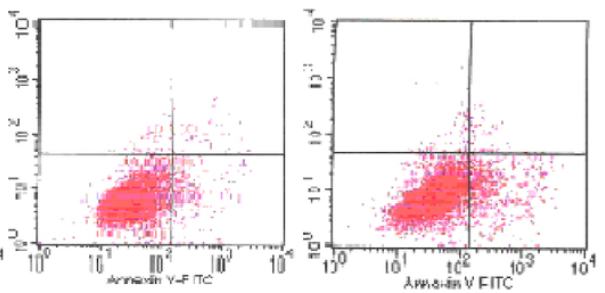

D

b-4

Figure 1 Morphological changes of the apoptosis in cancer cells were observed by AO/EB double fluorescent staining under fluorescent microscope (control groups in Figure 1a-1 and Figure 1b-1, group D in Figure 1-a2 and Figure 1-b2.), transmission electron microscope(group D in Figure 1-a3 and Figure 1-b3) and flow cytometry(Figure 1a-4 and Figure 1b-4). (SGC-7901 cells were in Figure 1a, SMMC-7721 cells in Figure 1b.).

radicals might induce apoptosis and necrosis in tumor cells via several targets, such as cell membranes, intracellular bioactive molecules, and DNA [19]. In this study, we found that low-frequency ultrasonic irradiation with microbubble agent promoted apoptosis and inhibited cellular proliferation in tumor cells and vascular endothelial cell. This effect was associated with the attenuation of the SOD activity in the culture medium. Consumption of active oxygen scavengers indicates an increase in the level of ROS produced during cellular damage caused by treatment with ultrasound and microbubble agent. This phenomenon has been assessed by other researchers who have suggested a sonochemical mechanism underlying this effect [20]. 


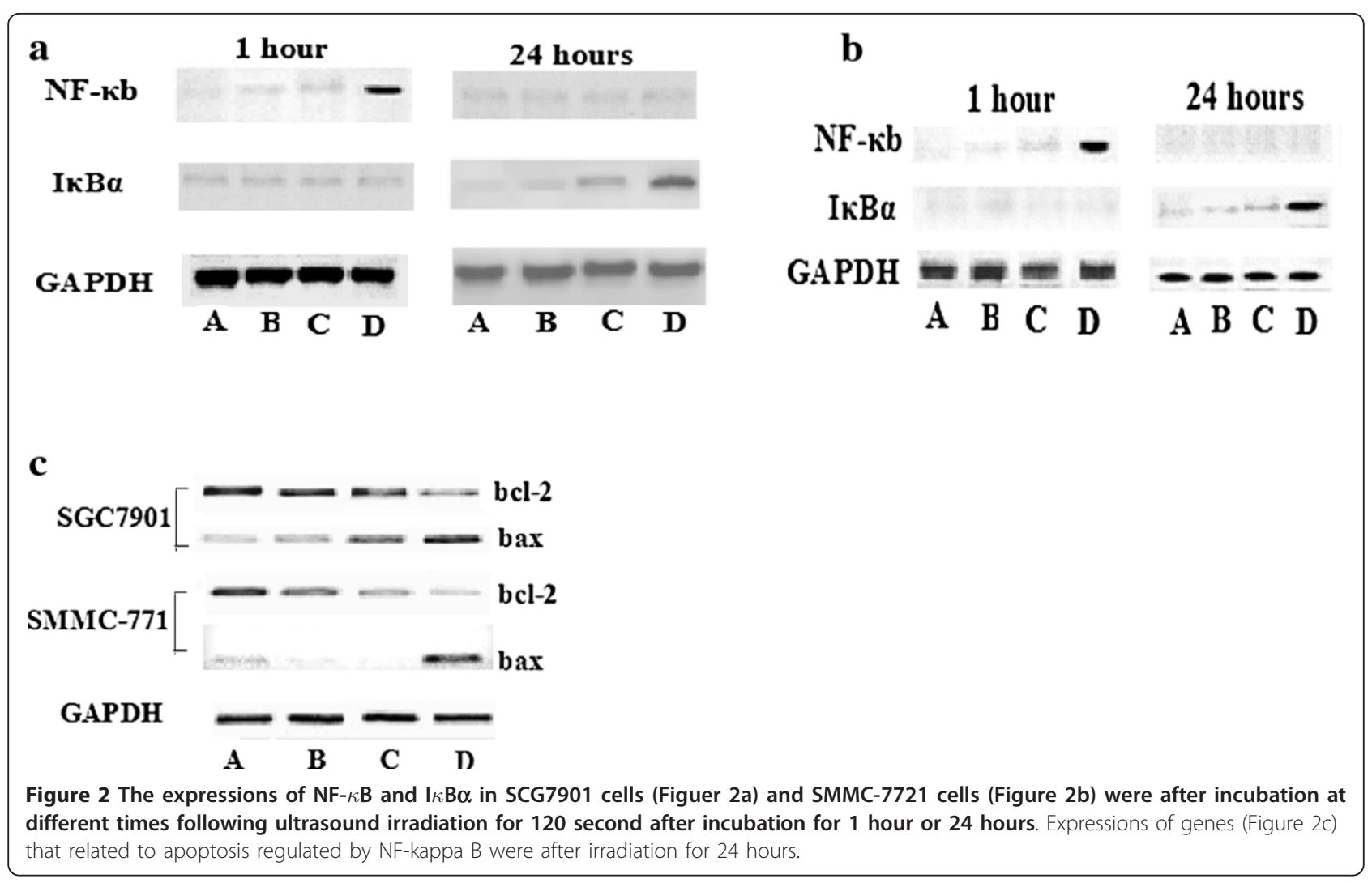

Apoptosis can be induced by treating cells with ultrasound and contrast agent. ROS-mediated injury may be one of the important factors responsible for the biological effects of ultrasound $[17,18]$. Increase in the expression of NF-kappa B and I kappa B-alfa has been often associated with the induction of apoptosis [14]. These nuclear factors might be related with the sequential induction of cell death caused by ultrasound.

ROS can activate the expression of intracellular NFkappa B. This ubiquitous cytokine is involved in the regulation of various cellular effectors molecules and is present in an inactive form as a dimer with I kappa B-alfa, in the absence of any stimulation. The activity of NF-kappa B proteins is regulated by I kappa B-alfa proteins [21]. When cells are stimulated, NF-kappa B is activated and is translocated to the nucleus, where it binds to the target gene promoter and activates its transcription [15]. A variety of extracellular signals can stimulate the activation of NFkappa B, such as ROS, ultraviolet irradiation, doublestranded RNA, cytokine interleukin-1, tumor necrosis factor- $\alpha$, lipopolysaccharide, and viruses [11-13]. Because the regulation by NF-kappa B activation, de novo I kappa Balfa can reintegrate with NF-kappa $B$ to form a dimeric compound to inhibit the activation of NF-kappa B. Although I kappa B-alfa is synthesized de novo, NF-kappa
$B$ activity remains sustainable for several hours [22]. We found that the protein level of NF-kappa B was markedly augmented at 1 hour after treatment with ultrasound irradiation and microbubble agent, suggesting that the cellular damage was associated with the oxidation induced by ultrasound and microbubbles. Hence, the biological effects of ultrasound were speculated to be associated with the ultrasound chemical reaction. At 24 hours after ultrasound treatment, the enhanced expression of I kappa B suggested that emerge of the activities of intracellular biological mediation produced through ultrasound chemical reactions, corresponding with the general regulation of modulating cellular proliferation in this type of cytokines $[21,22]$. We found that I kappa B-alfa expression promoted apoptosis in the experimental groups. Ultrasonic irradiation increased the level of ROS and induced the expression of NF-kappa B and I kappa B in succession. This finding suggests that the biological effect of sonochemistry is one of related factors in ultrasound killing cells with microbubble agent. Due to the dynamic characteristics of ultrasound contrast agents [5], ultrasound microbubble agents undergo reactions involved in ultrasound physics and ultrasound chemistry, damaging cell membranes and intracellular structures, and ultimately resulting in cellular injury or even cell death [23]. 


\section{Conclusion}

In this study, SMMC-771 tumor cells and SGC7901 cells were injured or induced apoptosis after treatment with low-frequency ultrasound with contrast agent. The apoptotic mechanism might be related to transitory expression of NF-kappa B stimulated by enhanced ultrasonic effect of contrast agent, and subsequent elevation in I kappa B alfa expression leads to the apoptosis and alterations of related apoptotic genes of cancer cells. The study results may provide experimental evidence or basis for using ultrasonic contrast agents to investigate their use in the treatment of cancer.

\section{Methods}

\section{Cells and culture medium}

Gastric cancer SGC7901 cell line and SMMC-7721 hepatoma cell line (Cell bank, Shanghai, China) were digested with $0.25 \%$ trypsin, and a single cell suspension was obtained; the cells were cultured in RPMI 1640 medium (GIBCO, USA) containing 10\% fetal calf serum (Sijiqing, Hangzhou, China), $100 \mathrm{U} / \mathrm{mL}$ of penicillin, and $100 \mathrm{mg} /$ $\mathrm{mL}$ of streptomycin at $37^{\circ} \mathrm{C}$ in a $5 \% \mathrm{CO}_{2}$ incubator. For all experiments, a cell density of $2 \times 10^{5} / \mathrm{mL}$ was used.

\section{Ultrasonic apparatus and contrast agents}

An ultrasonic surgical device (Jiangsu Meidakang, Nanjing, China) was used as an ultrasound apparatus, as described previously [24]. Before every experiment, the apparatus was adjusted using an Ultrasound power meter (Model UPM-DT-1; Ohnic Instruments Co., Maryland, Swiss). Experimental irradiation power was adjusted to $0.5 \mathrm{~W}$ on the reading meter, and an effective output value was adjusted to about $0.159 \mathrm{~W} / \mathrm{cm}^{2}$; this value was determined by measuring the outputs at $1 \mathrm{~W}, 0.5 \mathrm{~W}$, and $0.25 \mathrm{~W}$, according to the results of a preliminary experiment with the apparatus[25]. Contrast agent, Levovist (SHU 508A, Schering, Berlin, Germany) was added in $200 \mathrm{mg} / \mathrm{ml}$ into culture medium before ultrasound irradiation [8].

\section{Experimental design}

Two cell lines (SGC7901 and SMMC-7721) were divided into the following groups: a control group (A), without any interventions; simple microbubble group (B) that was treated with a simple microbubble agent alone; simple ultrasound group $(\mathrm{C})$ that was treated with ultrasound alone; and ultrasound combined with microbubble agent group (D). The groups that received ultrasonic irradiation were further divided into 4 subgroups according to the ultrasonic irradiation time of 60,90, 120, and 150 seconds. The cells treated with ultrasonic irradiation were placed in a latex finger glove. The glove was suspended under degassed water in a constant temperature bath, maintained at $37^{\circ} \mathrm{C}$ and was made to be in contact with a transducer placed inside the bucket. Immediately before exposing the cells to ultrasound, we added the microbubble contrast agent at a concentration of 1:3. After the treatment, the conditioned medium was replaced with a fresh one. For viability testing, $200 \mu \mathrm{l}$ of the sample was used, and the remaining sample was incubated for 1, 24 and 48 hours under the same conditions until further analysis.

\section{Measurement of cell survival rate}

Cell survival rate was measured using the methyl thiazolyl tetrazolium (MTT) assay kit (Sigma, USA). Absorption (A570) was measured at $570 \mathrm{~nm}$, and cell survival rate was calculated using the following formula: cell survival rate = [optical density value (experiment group)/optical density value (control group)] $\times 100 \%$.

\section{Measurement of reactive oxygen species (ROS) and superoxide dismutase (SOD) levels}

The level of intracellular ROS was evaluated with a fluorescent probe, 2',7'-dichlorofluorescin diacetate (DCFH-DA) in reactive oxygen species assay kit (Applygen Technologies Inc. Beijing, China) and a FACS Calibur (BD Pharmingen)[26]. The activities of superoxide dismutase (SOD) were assayed by the kits (Jiancheng Biotechnology Institute, Nanjing, China).

\section{Morphological survey}

The cells were observed under optics inverted microscope (OLYMPUS-CK2; Olympus, Japan) for routine morphological investigation. After treatment with the agents, the cells were also observed under a transmission electron microscope (Hitachi-660, Hitachi, Japan) after centrifugation at $1000 \mathrm{rpm}$ for $5 \mathrm{~min}, 2$ times each. Apoptotic morphological changes in the cells were detected by staining with AO/EB. Briefly, $1 \mathrm{ml}$ of a stock solution containing $100 \mathrm{mg} / \mathrm{ml}$ each of $\mathrm{AO}$ and EB was added to $25 \mathrm{ml}$ of cell suspension. Cells were examined using fluorescence microscopy. Viable cells were colored green with intact nuclei. Apoptosis was demonstrated by the appearance of orange cell shrinkagewith condensation and fragmentation of nuclei.

\section{Flow cytometry-mediated detection of apoptosis}

After the cells were treated with ultrasound irradiation, they were detected using the calcium-binding protein $\mathrm{V}$ fluorescein isothiocyanate (AnnexinV-FITC) staining kit (Immuno tech Co. France) by using a flow cytometer (Beckman Coulter, USA).

\section{Western blot}

Western blot analysis was performed for detecting the expressions of NF-kappa B, I kappa B alfa, bcl-2 and bax in the cells (SGC7901 cells or SMMC-7721 cells), as described in detail previously [13,22]. Enhanced chemiluminescence (ECL) (Santa Cruz, CA, USA) was used to 
detect the protein bands, and the results were analyzed using the BioProfil gel electrophoresis image analysis system after gray-scale integration of the electrophoresis bands corrected with glyceraldehyde-3-phosphate dehydrogenase (GAPDH) (Boaosheng, Beijing, China).

\section{Statistical analysis}

The experimental data were presented as mean \pm standard error and analyzed using statistical package for social sciences (SPSS) 13. 0 statistical software package. Numerical data were compared using analysis of variance (ANOVA). Statistical significance was set at $\alpha=$ 0.05 .

\section{Abbreviations}

DCFH-DA: 2',7'-dichlorofluorescin diacetate; ECL: enhanced

chemiluminescence; Bcl2: B cell lymphoma gene 2; GAPDH: glyceraldehyde3-phosphate dehydrogenase; AO/EB: acridine orange/ethidium bromide; FACS Calibur; fluorescent actived cell sortor or flow cytometer; MTT: methyl thiazolyl tetrazolium; ROS: reactive oxygen species; SOD: superoxide dismutase; NF-kappa B: nuclear factor kappa B.

\section{Acknowledgements}

We thank the editors and reviewers for their valuable comments and suggestions which are helpful for improving this manuscript. This work was supported in part by the preliminary research fund for the Natural Science foundation of Southeast University (XJ 0590214) and the National Natural Science Foundation (NSFC 10474073)

\section{Author details}

'Department of Oncology, Zhong-Da Hospital \& Clinical medical college, Southeast University, 87\# Ding-Jia-Qiao Road, Nanjing 210009, China. ${ }^{2}$ Key Laboratory of Environmental Medicine and Engineering, Minister of Education, Public health college, Southeast University, Nanjing, China. ${ }^{3}$ Acoustics institution, Tongji University, 200092 Shanghai, China. ${ }^{4}$ Department of Oncology, Zhongda Hospital, Southeast University/Key Laboratory of Environmental Medicine and Engineering, Minister of Education, Public health college, Southeast University, 87\# Ding-Jia-Qiao Road, Nanjing 210009, China.

\section{Authors' contributions}

$J Z$ performed the morphological survey, experimental design, analyzed the data, wrote and revised the manuscript. WW carried out cell culture, ultrasound treatment, the experiments of Western blotting, fluorescence staining and made the draft of the manuscript as co-first author. QML carried out experimental design of ultrasound principle. All authors read and approved the final manuscript.

\section{Competing interests}

The authors declare that they have no competing interests.

Received: 12 January 2012 Accepted: 15 March 2012 Published: 15 March 2012

\section{References}

1. Sergeeva NS, Sviridova IK, Nikolaev AL, Ambrozevich EG, Kabisov RK, Sarantseva OS, Kurilyak OA, Al'kov SV, Sokolov W: Effects of various modes of sanitation with low frequency ultrasound on in vitro survival of human tumor cells. Bull Exp Biol Med 2001, 131:279-282.

2. Lejbkowicz F, Salzberg S: Distinct sensitivity of normal and malignant cells to ultrasound in vitro. Environ Health Perspect 1997, 105(Suppl 6):1575-1578.

3. Zhai BJ, Wu F, Shao ZY, Hu K, Zhao CL, Wang ZB: Establishment of human hepatocellular carcinoma multidrug-resistance cell line (HepG2/Adm) and study apoptosis induced by low-frequency pulse ultrasound exposure. Zhonghua Gan Zang Bing Za Zhi 2004, 12:95-98.
4. Fuciarelli AF, Sisk EC, Thomas RM, Miller DL: Induction of base damage in DNA solutions by ultrasonic cavitation. Free Radic Biol Med 1995, 18:231-238.

5. Cheng Q, Qian ML: Low frequency dynamic behavior of ultrasound microbubble contrast agent. Tech Acoust 2006, 25:292-298.

6. Feril LB Jr, Kondo T, Zhao QL, Ogawa R, Tachibana K, Kudo N, Fujimoto S, Nakamura S: Enhancement of ultrasound-induced apoptosis and cell lysis by echo-contrast agents. Ultrasound Med Biol 2003, 29:331-337.

7. Furusawa Yukihiro, Zhao Qing-Li, Ali Hassan Mariame, Tabuchi Yoshiaki, Takasaki Ichiro, Wada Shigehito, Kondo Takashi: Ultrasound-induced apoptosis in the presence of Sonazoid and associated alterations in gene expression levels: A possible therapeutic application. Cancer Letters 2010, 288:107-115.

8. Ando Hidetaka, Feril BLoreto Jr, Kondo Takashi, Tabuchi Yoshiaki, Ogawa Ryohei, Zhao Qing-Li, Cui Zheng-Guo, Umemura Shin-ichiro, Yoshikawa Hideki, Misaki Takuro: An echo-contrast agent, Levovist, lowers the ultrasound intensity required to induce apoptosis of human leukemia cells. Cancer Letters 2006, 242:37-45.

9. Kondo T, Misík V, Riesz P: Effect of gas-containing microspheres and echo contrast agents on free radical formation by ultrasound. Free Radic Biol Med 1998, 25:605-612.

10. Millor DL, Quddus J: Sonoporation of monolayer cells by diagnostic ultrasound activation of contrast-agent gas bodies. Ultrasound Med Biol 2000, 26:661-667.

11. Angelica RB-P, Marlene J-Del-R, Carlos V-P: Vitamin K3 and vitamin C alone or in combination induced apoptosis in leukemia cells by a similar oxidative stress signalling mechanism. Cancer Cell Int 2011, 11:19.

12. Hunot S, Brugg B, Ricard D, Michel PP, Muriel MP, Ruberg M, Faucheux BA, Agid $Y$, Hirsch EC: Nuclear translocation of NF-kappaB is increased in dopaminergic neurons of patients with parkinson disease. Proc Natl Acad Sci USA 1997, 94:7531-7536.

13. Kaul N, Choi J, Forman HJ: Transmembrane redox signaling activates NFkappa B in macrophages. Free Radic Biol Med 1998, 24:202-207.

14. Chiao PJ, Miyamoto S, Verma IM: Autoregulation of I kappa B alpha activity. Proc Natl Acad Sci USA 1994, 91:28-32.

15. Liu ZG, Hsu H, Goeddel DV, Karin M: Dissection of TNF receptor 1 effector functions: JNK activation is not linked to apoptosis while NF-kappaB activation prevents cell death. Cell 1996, 87:565-576.

16. Honda H, Zhao QL, Kondo T: Effects of dissolved gases and an echo contrast agent on apoptosis induced by ultrasound and its mechanism via the mitochondria-caspase pathway. Ultrasound Med Biol 2002, 28:673-682.

17. Honda H, Kondo T, Zhao QL, Feril LB Jr, Kitagawa H: Role of intracellular calcium ions and reactive oxygen species in apoptosis induced by ultrasound. Ultrasound Med Biol 2004, 30:683-692.

18. Feril LB Jr, Kondo T, Ogawa R, Zhao QL: Dose-dependent inhibition of ultrasound-induced cell killing and free radical production by carbon dioxide. Ultrason Sonochem 2003, 10:81-84.

19. Skorpíková J, Dolníková M, Hrazdira I, Janisch R: Changes in microtubules and microfilaments due to a combined effect of ultrasound and cytostatics in HeLa cells. Folia Biol (Praha) 2001, 47:143-147.

20. Lagneaux L, de Meulenaer EC, Delforge A, Dejeneffe M, Massy M, Moerman C, Hannecart B, Canivet Y, Lepeltier MF, Bron D: Ultrasonic lowenergy treatment: a novel approach to induce apoptosis in human leukemic cells. Exp Hematol 2002, 30:1293-1301.

21. Kretz-Remy C, Arrigo AP: Selenium: a key element that controls NF-kappa B activation and I kappa B alpha half life. Biofactors 2001, 14:117-125.

22. Notarbartolo M, Poma P, Perri D, Dusonchet L, Cervello M, D'Alessandro N: Antitumor effects of curcumin, alone or in combination with cisplatin or doxorubicin, on human hepatic cancer cells. Analysis of their possible relationship to changes in NF-kB activation levels and in IAP gene expression. Cancer Lett 2005, 224:53-65.

23. Zachary JF, Blue JP, Miller RJ, O'Brien WD Jr: Vascular lesions and sthrombomodulin concentrations from auricular arteries of rabbits infused with microbubble contrast agent and exposed to pulsed ultrasound. Ultrasound Med Biol 2006, 32:1781-1791.

24. Wu W, Lin XB, Qian JM, Ji ZL, Jiang Z: Ultrasonic aspiration hepatectomy for 136 patients with hepatocellular carcinoma. World J Gastroenterol 2002, 8:763-765.

25. Wu W, Ning XB, Jiang Z, Guo XY, Feng R: Formation of micro-vessel embolization in rabbit liver induced by low power ultrasound irradiation 
combined with LEVOVIST agent. I Southeast Univ (Natural Science Edition, in chinese) 2003, 33:300-302.

26. Song H, Park H, Kim YS, Kim KD, Lee HK, Cho DH, Yang JW, Hur DY: Lkynurenine-induced apoptosis in human NK cells is mediated by reactive oxygen species. Int Immunopharmaco 2011, 11:932-938.

doi:10.1186/1475-2867-12-8

Cite this article as: Jiang et al.: Cellular damage and apoptosis along with changes in NF-kappa B expression were induced with contrast agent enhanced ultrasound in gastric cancer cells and hepatoma cells. Cancer Cell International 2012 12:8.

Submit your next manuscript to BioMed Central and take full advantage of:

- Convenient online submission

- Thorough peer review

- No space constraints or color figure charges

- Immediate publication on acceptance

- Inclusion in PubMed, CAS, Scopus and Google Scholar

- Research which is freely available for redistribution

Submit your manuscript at www.biomedcentral.com/submit
Ciomed Central 